\title{
Delirium Awareness and Treatment Approach in Orthopedics Clinic
}

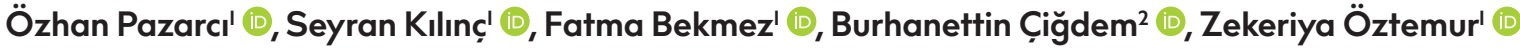 \\ 'Department of Orthopaedics and Traumatology, Cumhuriyet University School of Medicine, Sivas, Turkey \\ ${ }^{2}$ Department of Neurology, Cumhuriyet University School of Medicine, Sivas, Turkey
}

ORCID IDs of the authors: Ö.P. 0000-0002-2345-0827; S.K. 0000-0003-0I44-09I6; F.B. 0000-000I-5839-6974; B.C̣. 0000-0003-494I9497; Z.Ö. 0000-0003-2134-8797.

\author{
Cite this article as: Pazarcı Ö, Kılınç S, Bekmez F, Çiğdem B, Öztemur Z. Delirium Awareness and Treatment Approach in Orthopedics \\ Clinic. Cyprus J Med Sci 2020; 5(I): 26-30.
}

\section{BACKGROUND/AIMS}

Orthopedic clinics are among the leading clinics in hospitals that request consultation for patients with delirium. However, delirium is often missed by nurses and physicians, resulting in an incorrect diagnosis. This study aimed to identify patients with delirium in the orthopedic clinics and describe our approach for these patients.

\section{MATERIAL and METHODS}

After forming a strategy for the diagnosis, treatment, and follow-up of patients with delirium, prospective follow-up was performed for patients hospitalized in the orthopedic ward. High-risk patients were screened using the Nursing Delirium Screening Scale, and patients diagnosed with delirium were evaluated using a prepared form. This approach was used to determine the risk factors for delirium, ensure patient safety, and treat the symptoms of delirium.

\section{RESULTS}

Total 988 patients were evaluated, and $34(2.44 \%)$ were diagnosed with delirium. The mean age of the patients was $66.17 \pm 22.68$ years. The mean duration of delirium was $2.88 \pm 0.84$ days. An age group-based comparison showed that the duration of delirium in older patients was significantly longer than that in younger patients ( $3.08 \pm 0.9$ vs. $2.45 \pm 0.52 \mathrm{~d}, p=0.042)$. Further, delirium duration was more among men than among women (3.0 vs. $2.2 \mathrm{~d}, \mathrm{p}=0.03 \mathrm{l})$.

\section{CONCLUSION}

Rapid identification of delirium and determination of the etiological cause allows timely and appropriate correction of the condition Identification of delirium by the medical team and the use of a systemic approach are important in treatment. The duration of delirium is longer in men and the elderly; further, most delirious patients have more than one risk factor for delirium.

Keywords: Approaches, delirium, orthopaedics, treatment

\section{INTRODUCTION}

Delirium is an acute organic brain syndrome (I). In preoperative or postoperative patients in orthopedic clinics, a delirium table may be seen; a delirium table is a clinical disease characterized by acute onset and fluctuating course of attention, cognitive function, and mood disorders. Delirium is an important geriatric syndrome (2); although it may be present in young patients as well as in the elderly, it is usually overlooked or neglected (3). Delirium is important because it causes severe morbidity and even mortality; however, in the absence of awareness regarding this condition, diagnosis is difficult. There are established diagnostic criteria for delirium, and when it is diagnosed, its complications can be prevented. However, the diagnosis is missed out in $30 \%-60 \%$ of all cases. The development of delirium in patients prolongs their hospital stay, reduces their functional capacity, and increases the healthcare costs (4). In addition, it can result in permanent cognitive disorder, pressure sores, falls, pneumonia, increased mortality, and increased rate of moves to residential care homes. Worldwide, the rates of delirium are accepted as a marker of the quality of healthcare services.

Majority of hospital consultations requested because of delirium are from orthopedic clinics (5). The reported frequency of delirium cases encountered in orthopedic clinics varies. Elderly patients with hip fracture constitute the highest-risk group among all orthopedic patients, and the reported delirium rates among this patient group are 6\%-61\% (6, 7). The 
wide variation in these rates is largely attributable to the frequent overlooking and misdiagnosis of delirium by nurses and physicians (8). The approach to delirium and its treatment show variations in the literature (9). Therefore, this study aimed to identify patients with delirium in the orthopedic clinics and describe our approach strategy for these patients.

\section{MATERIAL and METHODS}

A team comprising an orthopedic-ward nurse, an orthopedist, and a neurologist was informed about delirium and received training about this condition. A treatment and follow-up strategy was formed for these patients. Thereafter, patients admitted and treated at the orthopedic and traumatology clinic from January I to December 3I 2018 were enrolled in the study.

Approval for the study was granted by the local ethics committee. Patient data were collected prospectively. According to the approach strategy for patients with delirium that has been defined in Figure I, for each patient with acute onset of distraction and cognitive function disorder, the Nursing Delirium Screening Scale (Nu-DESC) was used. Those with a Nu-DESC score of $\geq 2$ were evaluated for delirium. A neurological consultation was requested for the patients. Delirium was diagnosed based on the DSM- $V$ diagnosis criteria, and those diagnosed with delirium were examined to understand the etiology, as shown in Table I. The causes of delirium that were determined were then treated.

Patients were excluded from the study if they were day-case patients; were < 18 y old; had a history of dementia, depression, or other psychiatric disorders; had metastatic cancer; or had a

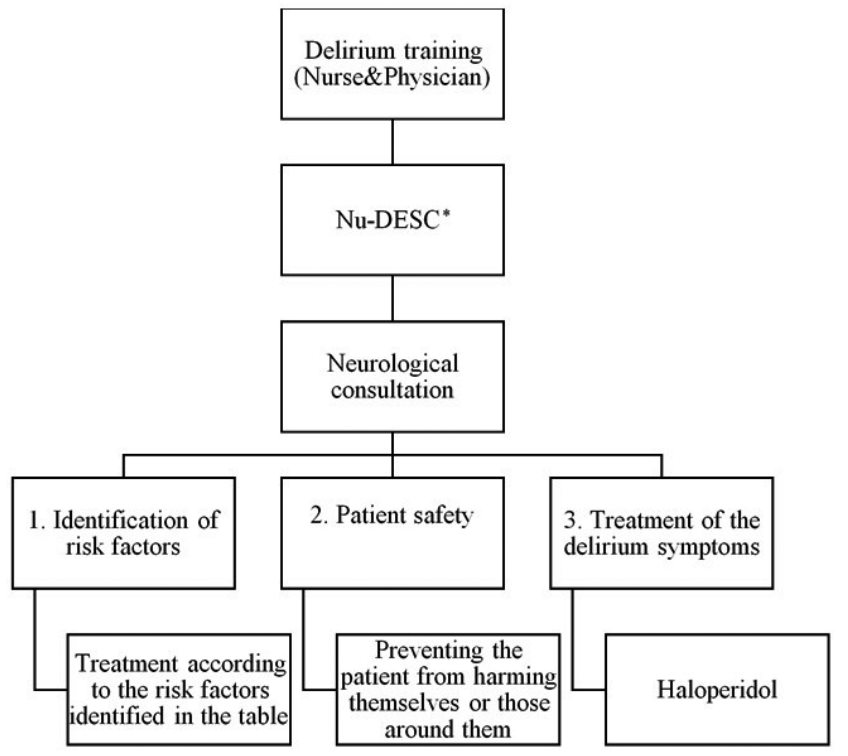

FIGURE I. Schematic diagram of the approach to patients with delirium in the orthopedic clinic

*Nu-DESC: The Nursing Delirium Screening Scale

\section{Main Points:}

- A timely and early diagnosis of delirium is important.

- A team approach is important for delirium treatment.

- The duration of delirium is longer in men and the elderly.

- Most patients have more than one risk factor for delirium. life expectancy of $<6$ months. Total 988 patients were examined, and for 38, a neurological consultation was requested with a pre-diagnosis of delirium. According to the DSM-V, 4 patients were not diagnosed with delirium. Thus, 34 patients were diagnosed with delirium and were followed up using the prepared form (Table I)

The diagnoses and demographic data of the patients were recorded. The patients were compared in terms of the duration of delirium, sex, age (classified as young if $<65$ years old and elderly if aged $\geq 65$ years old), and risk factors.

\section{Statistical Analyses}

Data obtained in the study were analyzed statistically using IBM Statistical Package for the Social Sciences version 22 software (SPSS IBM Corp.; Armonk, NY, USA). Conformity of the data to normal distribution was assessed using the Shapiro-Wilk test. For the comparison of 2 independent groups, the t-test was applied to parametric data and the Mann Whitney U-test was used for the non-parametric data. Data obtained from counts were evaluated using the Chi-square test. A $p$ value $<0.05$ was accepted as statistically significant.

\section{RESULTS}

Of the 988 patients evaluated in the study, 34 (3.44\%) were diagnosed with delirium. The mean patient age was $66.17 \pm 22.68 \mathrm{y}$. When the patients were classified as per age group, the mean age of the "young" group (those aged <65 y) was $37.36 \pm 15.88$ $y$, while that of the "elderly" group (those aged $\geq 65 \mathrm{y}$ ) was $79.95 \pm 6.59 y$.

The patients were classified as per their diagnosis as follows: $26(76.5 \%)$ had hip fracture, 5 (14.7\%) had multiple trauma, and 3 $(8.8 \%)$ had fractures in other regions. Fewer than 4 risk factors

TABLE I. Delirium Patient Etiology Evaluation Form
Patient information Day I Day 2 Day 3
I. Vital signs
2. Blood glucose level
3. Need for control of falling
4. Intracranial bleeding
5. Pain score
6. Infection
7. Dehydration
8. Withdrawal syndrome
9. Urinary retention
10. Constipation
II. Cardio/Pulmonary problems
12. Electrolyte imbalance
13. Immobilization
14. Vision impairment
15. Insomnia
16. Inappropriate drug use
17. Disorientation
18. Physical restraint


for delirium were determined in $19(55.9 \%)$ patients and more than 4 in 15 (44.1\%) (Figure 2).

\begin{tabular}{|c|c|c|c|c|}
\hline & & & $N$ & $\%$ \\
\hline \multirow{2}{*}{\multicolumn{2}{|c|}{ I. Sex }} & Male & 29 & 85.3 \\
\hline & & Female & 5 & 14.7 \\
\hline \multirow{3}{*}{\multicolumn{2}{|c|}{ 2. Diagnosis }} & Hip fracture & 26 & 76.5 \\
\hline & & Multiple Trauma & 5 & 14.7 \\
\hline & & Other region fractures & 3 & 8.8 \\
\hline \multirow{2}{*}{\multicolumn{2}{|c|}{ 3. Age }} & $<65 y$ & $\|$ & 32.4 \\
\hline & & $\geq 65 y$ & 23 & 67.6 \\
\hline \multirow[t]{2}{*}{4.} & Problems in vital signs & Absent & 20 & 58.8 \\
\hline & & Present & 14 & 41.2 \\
\hline \multirow[t]{2}{*}{5.} & Blood glucose level & Normal & 26 & 76.5 \\
\hline & & High & 8 & 23.5 \\
\hline \multirow[t]{2}{*}{6.} & Need for control of falling & Absent & 15 & 44.1 \\
\hline & & Present & 19 & 55.9 \\
\hline \multirow[t]{2}{*}{7.} & Intracranial bleeding & Absent & 33 & 97.1 \\
\hline & & Present & 1 & 2.9 \\
\hline \multirow[t]{2}{*}{8.} & Infection & Absent & 31 & 91.2 \\
\hline & & Present & 3 & 8.8 \\
\hline \multirow[t]{2}{*}{9.} & Dehydration & Absent & 25 & 73.5 \\
\hline & & Present & 9 & 26.5 \\
\hline \multirow[t]{2}{*}{10.} & Withdrawal syndrome & Absent & 32 & 94.1 \\
\hline & & Present & 2 & 5.9 \\
\hline \multirow[t]{2}{*}{ II. } & Urinary retention & Absent & 33 & 97.1 \\
\hline & & Present & 1 & 2.9 \\
\hline \multirow[t]{2}{*}{12.} & Constipation & Absent & 23 & 67.6 \\
\hline & & Present & $\|$ & 32.4 \\
\hline \multirow[t]{2}{*}{13.} & Cardiopulmonary problem & Absent & 32 & 94.1 \\
\hline & & Present & 2 & 5.9 \\
\hline \multirow[t]{2}{*}{14.} & Electrolyte imbalance & Absent & 15 & 44.1 \\
\hline & & Present & 19 & 55.9 \\
\hline \multirow[t]{2}{*}{15.} & Immobilization & Absent & 23 & 67.6 \\
\hline & & Present & $\|$ & 32.4 \\
\hline \multirow[t]{2}{*}{16.} & Vision impairment & Absent & 32 & 94.1 \\
\hline & & Present & 2 & 5.9 \\
\hline \multirow[t]{2}{*}{17.} & Insomnia & Absent & 22 & 64.7 \\
\hline & & Present & 12 & 35.3 \\
\hline \multirow[t]{2}{*}{18.} & Inappropriate drug use & Absent & 32 & 94.1 \\
\hline & & Present & 2 & 5.9 \\
\hline \multirow[t]{2}{*}{19.} & Disorientation & Absent & 0 & 0 \\
\hline & & Present & 34 & 100 \\
\hline \multirow{2}{*}{\multicolumn{2}{|c|}{ 20. Physical restraint }} & Absent & 19 & 55.9 \\
\hline & & Present & 15 & 44.1 \\
\hline \multirow{2}{*}{\multicolumn{2}{|c|}{ 21. Pain }} & Normal/moderate & 17 & 50.0 \\
\hline & & Severe & 17 & 50.0 \\
\hline
\end{tabular}

Severe pain, elevated blood glucose level, and the presence of $>$ 4 risk factors influenced the duration of delirium (p: 0.627, p: 0.113, and p: 0.851 , respectively). The mean blood glucose level was $151.67 \pm 58.57 \mathrm{mg} / \mathrm{dL}$. The findings are shown in Table 2 .

The mean duration of delirium was $2.88 \pm 0.84 \mathrm{~d}$. An age-group based comparison showed that the duration of delirium was significantly longer in the older patients than in the younger patients $(3.08 \pm 0.9$ vs. $2.45 \pm 0.52 d, p=0.042)$. Further, men had significantly longer duration of delirium than women (3.0 vs. $2.2 \mathrm{~d}$, $p=0.03 I$ ).

\section{DISCUSSION}

This study can be considered valuable because it presents an approach for the treatment of delirium that is frequently observed in patients in orthopedic clinics. Early diagnosis is crucial in the prevention of delirium and its effects (I0). Considering the increase in the elderly population and the prevalence of hip fracture, it can be predicted that there will be an increase in the incidence of delirium (8). Therefore, awareness regarding delirium and good management are important. In this study, the prevalence of delirium in the orthopedic patients was $3.44 \%$. In the literature, the incidence rates of delirium are reported to be increasing, with higher rates in the elderly. The reported incidence rate of postoperative delirium in patients who have undergone hip surgery is $4 \%-61 \%$ (II).

According to the neuroinflammatory hypothesis, delirium represents the central nervous system manifestation of a systemic disease state that has crossed the blood-brain barrier. Inflammation has been recognized as a trigger for episodes of delirium, particularly in older adults, with a correlation between the severity of the patient's underlying medical problem and the development of delirium. Systemic inflammatory events trigger the release of inflammatory mediators by tissue macrophages and brain vascular endothelial cells. These mediators may have a direct effect on the neuronal function or indirect effect via the activation of microglial cells that have become primed by neurodegenerative disease or aging. Inflammatory mediators may cause reversible disruption of neuronal function, as in the case of delirium; they may be irreversible and contribute to long-term cognitive decline or may cause neuronal death, contributing to the accumulating damage and neuropathological burden (12).

A team approach was adopted for the patients in the current study; the team comprised an orthopedist, a nurse, and a neu-

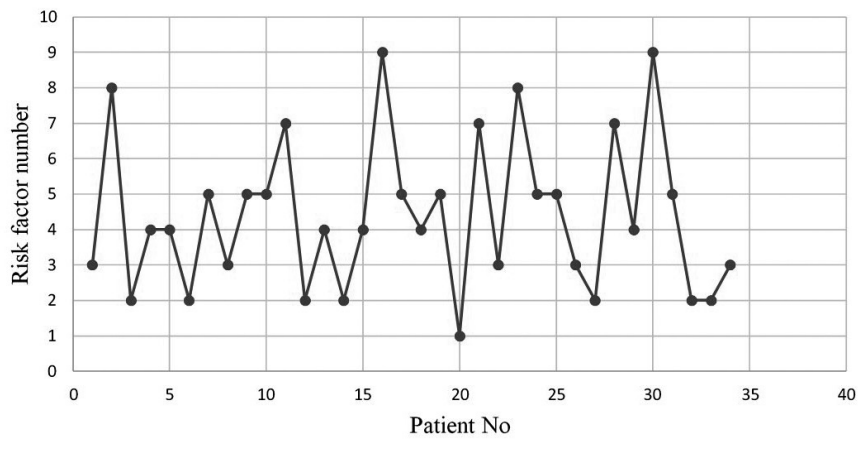

FIGURE 2. Number of risk factors determined in each patient 
rologist. The importance of a multidisciplinary team approach for patients with delirium has been emphasized in the literature $(8,13)$. There are 3 goals in the treatment of delirium, as follows: i) to determine the etiological cause, ii) to ensure patient safety, and iii) to treat the symptoms of delirium. The training of physicians, particularly nurses, who are working in the clinic, is important for timely and accurate diagnosis and management of delirium (8). The use of the Nu-DESC enables rapid screening of delirium (14).

Different studies have reported varying duration of delirium (4). In the current study, the mean duration of delirium was $2.88 \pm 0.84 \mathrm{~d}$, and the duration was longer in men and the elderly. Previous studies have also shown that delirium lasted longer in men and that there was a correlation of delirium duration with age (15). Several studies have shown that the delirium duration can be $<1$ wk or $>1$ wk (16). Daily follow-up and evaluation of the patient is crucial for delirium of short delirium, as in the current study (15).

Recent trials support the approach for delirium patients recommended in this study. It has been emphasized in the literature that geriatric multimodal consultation has reduced the rates of delirium among the elderly (17). Disruptions in the electrolyte levels in the body, changes in the blood glucose levels, cardiopulmonary problems, and drug or substance withdrawal syndromes, are predisposing factors for delirium. In addition, the inappropriate use of drugs, such as polypharmacy with the use of $>4$ different drugs or the initiation of $>3$ new drugs in the previous $24 \mathrm{~h}$ is also implicated as a risk factor. Patients presenting with a delirium table must be investigated for infection focus. Delirium rarely has a single cause and is usually multifactorial (18). On the follow-up form used in the current study, in addition to age, sex, and diagnosis data, 18 etiological parameters were evaluated (Table I). The delirium risk factors that were determined were treated. It has been frequently emphasized in the literature that the identification of risk factors is the critical first step in the prevention and rapid treatment of delirium (18). However, the present results showed no significant difference in the delirium duration, irrespective of the number of risk factors present. Various drugs are used in the treatment of delirium and its symptoms (9). The use of Haloperidol is supported by previous reports in studies for a rapid effect in delirium treatment (8). Therefore, Haloperidol was used in the current study approach for treating delirium symptoms, as emphasized in the literature. In addition to pharmacological treatment, the non-pharmacological treatment approach is a part of delirium treatment. This is implemented with methods that will provide time and spatial orientation for the patient, such as staying in a quiet room, being accompanied by a family member or known caretaker, and the presence of a clock and television in the room (19). In the current study, a non-pharmacological approach constituted a part of the treatment for delirium patients.

There are certain limitations to this study. Although it was a prospective study, the relatively lower sample size precluded the formation of a control group. Thus, further multi-center prospective studies are warranted to support the use of the treatment approach presented here.
In conclusion, timely diagnosis of delirium and identification of the etiological cause allows the delirium table to be quickly and properly corrected. There is no single recommendation for the treatment and management of patients with delirium; however, a team approach is important for the awareness of delirium and a systematic approach to treatment. The duration of delirium is longer in men and the elderly, and most patients have more than one risk factor for delirium.

Ethics Committee Approval: Ethics committee approval was received for this study from the Local Ethics Committee (Date: 02.01.2019, No: 20190l/06)

Informed Consent: Written informed consent was obtained from patients who participated in this study.

Peer-review: Externally peer-reviewed.

Author contributions: Concept - O.P.; Design - O.P., S.K.; Supervision Z.O., B.C.; Resource - O.P., F.B.; Materials - O.P.; Data Collection and/or Processing - F.B., O.P., S.K.; Analysis and/or Interpretation - S.K., B.C.; Literature Search - O.P., S.K., B.C.; Writing - O.P., Z.O.; Critical Reviews -Z.O., B.C.

Conflict of Interest: The authors have no conflicts of interest to declare.

Financial Disclosure: The authors declared that this study has received no financial support.

\section{REFERENCES}

I. Setters B, Solberg LM. Delirium. Prim Care Clin Off Pract 2017; 44(3): 54I-59. [CrossRef]

2. Inouye SK, Westendorp RG, Saczynski JS. Delirium in elderly people. Lancet 2014; 383(9920): 911-22. [CrossRef]

3. Grover S, Malhotra S, Bharadwaj R, Bn S, Kumar S. Delirium in Children and Adolescents. Int J Psychiatry Med 2009; 39(2): 179-87. [CrossRef]

4. Weinrebe W, Johannsdottir E, Karaman M, Füsgen I. Was kostet ein Delir?: Eine ökonomische Bewertung des hypermotorischen Delirs. Z Gerontol Geriatr 2016; 49(I): 52-8. [CrossRef]

5. Rizk P, Morris W, Oladeji P, Huo M. Review of Postoperative Delirium in Geriatric Patients Undergoing Hip Surgery. Geriatr Orthop Surg Rehabil 2016; 7(2): 100-5. [CrossRef]

6. Edelstein DM, Aharonoff GB, Karp A, Capla EL, Zuckerman $J D$, Koval KJ. Effect of postoperative delirium on outcome after hip fracture. Clin Orthop Relat Res 2004; (422): 195-200. [CrossRef]

7. Braver C, Morrison RS, Silberzweig SB, Siu AL. The cause of delirium in patients with hip fracture. Arch Intern Med 2000; 160(12): 1856-60. [CrossRef]

8. Neitzel J, Sendelbach S, Larson LR. Delirium in the orthopaedic patient. Orthop Nurs 2007; 26(6): 354-63. [CrossRef]

9. Carnes M, Howell T, Rosenberg M, Francis J, Hildebrand C, Knuppel J. Physicians vary in approaches to the clinical management of delirium. J Am Geriatr Soc 2003; 5I(2): 234-9. [CrossRef]

10. Bölüktaș RP. Assessment, prevention, and management strategies of delirium in elderly patients in intensive care units. Yoğun Bakım Hemșireliği Derg 2015; 19(2): 68-79.

II. Smith TO, Cooper A, Peryer G, Griffiths R, Fox C, Cross J. Factors predicting incidence of post-operative delirium in older people following hip fracture surgery: a systematic review and meta-analysis. Int J Geriatr Psychiatry 2017; 32(4): 386-96. [CrossRef]

12. Maldonado JR. Delirium pathophysiology: An updated hypothesis of the etiology of acute brain failure. Int J Geriatr Psychiatry 2018; 33(II): 1428-57. [CrossRef] 
13. Inouye SK, Bogardus ST, Charpentier PA, Leo-Summers L, Acampora $\mathrm{D}$, Holford TR, et al. A Multicomponent Intervention to Prevent Delirium in Hospitalized Older Patients. N Engl J Med 2002; 340(9): 669-76. [CrossRef]

14. Gaudreau JD, Gagnon P, Harel F, Tremblay A, Roy MA. Fast, systematic, and continuous delirium assessment in hospitalized patients: The nursing delirium screening scale. J Pain Symptom Manage 2005; 29(4): 368-75. [CrossRef]

15. Slor CJ, Witlox J, Adamis D, Meagher DJ, Ploeg T Van Der, Jansen RWMM, et al. Predicting Delirium Duration in Elderly Hip-Surgery Patients: Does Early Symptom Profile Matter? Curr Gerontol Geriatr Res 2013; 2013(1997): 1-9. [CrossRef]
16. Weckmann M. Delirium Incidence and Cause in Younger Hospitalized Patients With Advanced Cancer (783). J Pain Symptom Manage 2012; 43(2): 470. [CrossRef]

17. Zhang $H$, Lu Y, Liu M, Zou Z, Wang L, Xu FY, et al. Strategies for prevention of postoperative delirium: A systematic review and meta-analysis of randomized trials. Crit Care 2013; 17(2): R47. [CrossRef]

18. Inouye SK, Zhang Y, Jones RN, Kiely DK, Yang F, Marcantonio ER. Risk Factors for Delirium at Discharge. Arch Intern Med 2007; 167(I3): 1406. [CrossRef]

19. Hipp DM, Ely EW. Pharmacological and Nonpharmacological Management of Delirium in Critically III Patients. Neurotherapeutics 2012; 9(I): 158-75. [CrossRef] 